\title{
Studies on the laccase-mediated decolorization, kinetic, and microtoxicity of some synthetic azo dyes
}

\author{
Hamid Forootanfar ${ }^{1}$, Shahla Rezaei ${ }^{2}$, Hamed Zeinvand-Lorestani ${ }^{3}$, Hamed Tahmasbi ${ }^{2}$, Mehdi Mogharabi ${ }^{2}$, \\ Alieh Ameri ${ }^{4}$ and Mohammad Ali Faramarzi ${ }^{2 *}$
}

\begin{abstract}
Background: Enzymatic elimination of synthetic dyes, one of the most environmentally hazardous chemicals, has gained a great interest during the two last decades. The present study was performed to evaluate the decolorization and detoxification potential of the purified laccase of Paraconiothyrium variabile in both non-assisted and hydroxybenzotriazole-aided form against six azo dyes.

Results: The obtained results showed that Acid Orange 67, Disperse Yellow 79, Basic Yellow 28, Basic Red 18, Direct Yellow 107, and Direct Black 166 were decolorized up to 65.3, 53.3, 46.7, 40.7, 34, and $26.2 \%$, respectively, after $1 \mathrm{~h}$ treatment with laccase $(0.5 \mathrm{U} / \mathrm{mL})$. Addition of HBT up to $5 \mathrm{mM}$ enhanced decolorization percent of all the investigated dyes. The results of kinetic study introduced the monoazo dye of Acid Orange 67 as the most suitable substrate for laccase with $K_{m}$ of $0.49 \mathrm{mM}$ and $V_{\max }$ of $189 \mathrm{mmol} / \mathrm{min} / \mathrm{mg}$. Evaluation the toxic effect of laccase-treated dye sample based on the growth inhibition of standard bacterial strains revealed decrease in toxicity of all applied dyes after treatment by laccase.
\end{abstract}

Conclusions: Application of the P. variabile laccase as biocatalyst efficiently decreased the toxicity of all studied synthetic azo dyes.

Keywords: Decolorization, Detoxification, Laccase, Hydroxybenzotriazole, Microtoxicity

\section{Background}

Synthetic dyes are being increasingly applied in the textile, paper, cosmetics, pharmaceutical, leather dyeing, color photography, and food industries [1-4]. Azo dyes (contain the $\mathrm{N}=\mathrm{N}$ group in their structure) identified as one of the most popular synthetic colorant agent because they could be easily and affordably synthesized and found to be stable [5-7]. However, the toxicity, mutagenicity, and carcinogenicity of synthetic azo dyes and/or their metabolites have been well documented [8-10]. Furthermore, the harmful effects of azo dyes on the germination and growth of many environmentally important plants have been well described $[1,10]$. So, development of physicochemical $[11,12]$ and/or biological

\footnotetext{
* Correspondence: faramarz@tums.ac.ir

2Department of Pharmaceutical Biotechnology, Faculty of Pharmacy and Biotechnology Research Center, Tehran University of Medical Sciences, P.O. Box 14155-6451, Tehran 1417614411, Iran

Full list of author information is available at the end of the article
}

techniques for treatment of wastewater rich in such complex aromatic structures received great attention during the two last decades among which enzymatic removal of such pollutants is an economic and environmentally friendly procedure due to the low energy required and the minimal impact on ecosystems [13-15].

Laccases (EC 1.10.3.2), the multicopper-containing oxidases belonging to the superfamily of multicopper oxidase, are mainly produced by plants, fungi especially the white-rot basidiomycetes and some bacterial strains [16-18]. Laccases alone or in assistance with mediators have been found to catalyze the oxidation of a broad range of substrates such as phenol and its derivatives, benzenethiols, aromatic amines, and polycyclic aromatic hydrocarbons (PAHs) [19-21]. The mentioned feature launched these biocatalysts as the main tool in the xenobiotic removal studies [22, 23]. There are many reports on the application of the purified laccases or 
laccase-producing organisms for elimination of synthetic and natural dyes [24, 25]. For example, the ability of laccase from Trametes versicolor for decolorization of four dyes including Red FN-2BL, Red BWS, Remazol Blue RR and Blue 4BL was reported by Mendoza et al. [26]. In the study of Yan et al. [27] two azo dyes including reactive black and congo red decolorized by the crude laccase of Trametes trogii S0301.

In the present study the potential application of the purified laccase originated from a soil-isolated fungal strain [25] for decolorization and detoxification of 6 synthetic azo dyes was evaluated. Thereafter, the effects of factors including $\mathrm{pH}$ and temperature as well as enzyme and mediator concentration on decolorization percent were also demonstrated. Additionally, the energetic $(\Delta S$, $\Delta \mathrm{H}$, and $\mathrm{Ea})$ and kinetic $\left(K_{\mathrm{m}}\right.$ and $\left.V_{\max }\right)$ parameters for laccase-mediated decolorization were determined.

\section{Methods}

\section{Chemicals and enzyme}

The six applied azo dyes (Fig. 1 and Table 1) were supplied by Alvan Sabet Co. (Tehran, Iran). 2,2'-Azinobis-(3-ethylbenzothiazoline-6-sulfonate) (ABTS) and 1-hydroxyben zotriazole (HBT) were provided by Sigma-Aldrich (St. Louis, MO, USA) and Merck (Darmstadt, Germany), respectively. The laccase applied in the present study was purified as previously described [25].

\section{Laccase assay}

The previously reported method of Forootanfar et al. [25] using ABTS was applied for measuring the oxidative activity of laccase. In brief, into the $0.5 \mathrm{~mL}$ freshly prepared enzyme substrate (ABTS $5 \mathrm{mM}$ in citrate buffer $100 \mathrm{mM} \mathrm{pH} 5)$ enzyme sample $(0.5 \mathrm{~mL})$ was added and the reaction mixture was incubated at $37{ }^{\circ} \mathrm{C}$ and

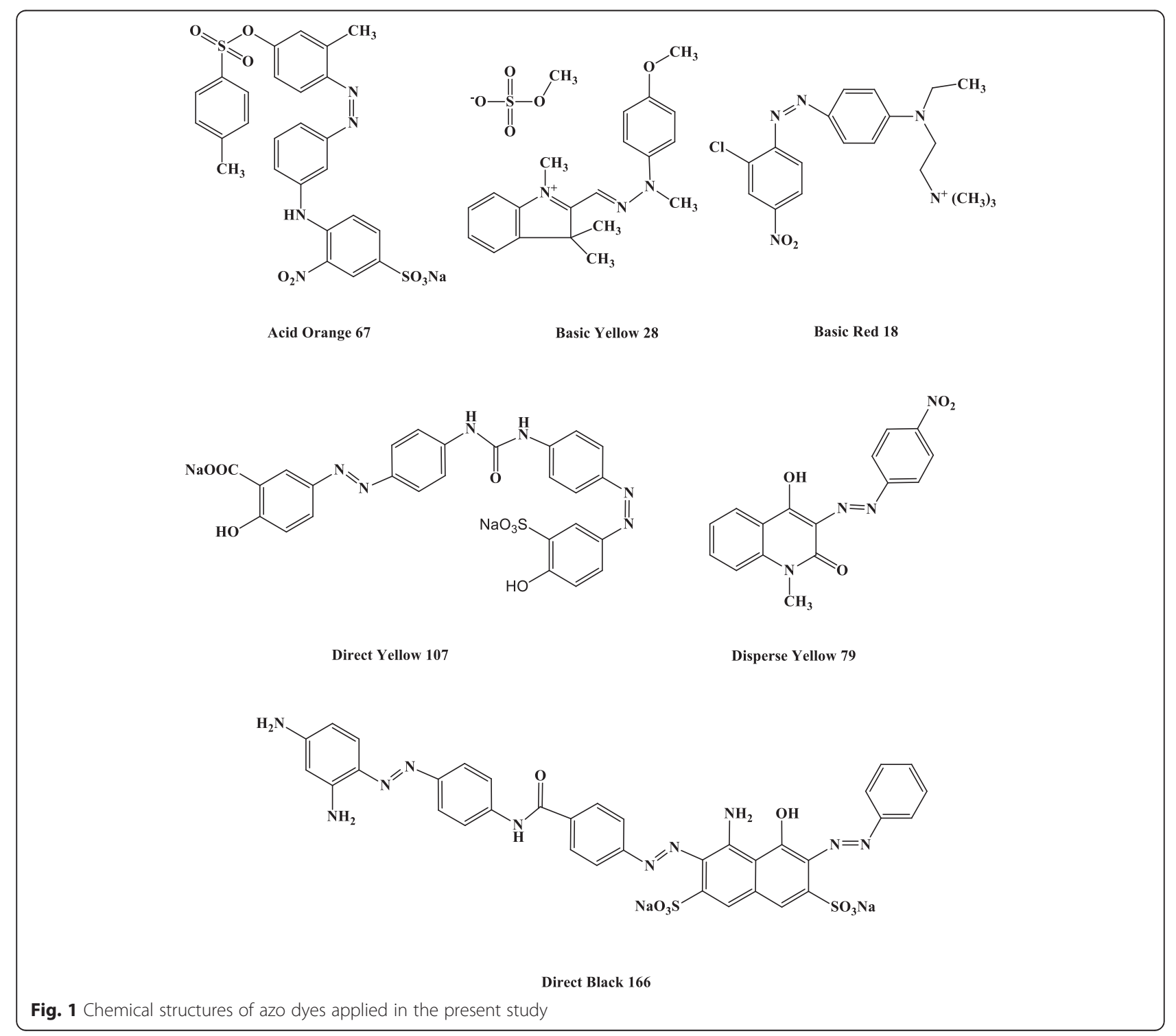


Table 1 Kinetic and energetic parameters of the laccase on studied synthetic dyes

\begin{tabular}{|c|c|c|c|c|c|c|c|}
\hline Dye name & Type & $\lambda_{\max }(\mathrm{nm})$ & $K_{\mathrm{m}}(\mathrm{mM})$ & $V_{\max }(\mathrm{mmol} / \mathrm{min} / \mathrm{mg})$ & $\Delta \mathrm{S}(\mathrm{Kj} / \mathrm{mol} / \mathrm{K})$ & $\Delta \mathrm{H}(\mathrm{kJ} / \mathrm{mol})$ & $\mathrm{Ea}(\mathrm{kJ} / \mathrm{mol})$ \\
\hline Acid Orange 67 & Monoazo & 438 & 0.49 & 189 & 307 & 93 & 24 \\
\hline Basic Red 18 & Monoazo & 489 & 3.07 & 64 & 194 & 63 & 28 \\
\hline Basic Yellow 28 & Monoazo & 450 & 2.07 & 100 & 308 & 91 & 29 \\
\hline Disperse Yellow 79 & Monoazo & 474 & 2.02 & 104 & 189 & 58 & 30 \\
\hline Direct Yellow 107 & Diazo & 368 & 3.44 & 47 & 213 & 68 & 26 \\
\hline Direct Black 166 & Triazo & 602 & 4.25 & 33 & 199 & 65 & 31 \\
\hline
\end{tabular}

$120 \mathrm{rpm}$ for $10 \mathrm{~min}$. Afterwards, the absorbance was recorded at $420 \mathrm{~nm}\left(\varepsilon_{420}=36,000 \mathrm{M}^{-1} \mathrm{~cm}^{-1}\right)$ by a Double Beam PC Scanning UV-vis spectrophotometer (UVD 2950, Labomed, Culver City, USA). The amount of enzyme which oxidize $1 \mu \mathrm{mol}$ of ABTS per minute defined as one unit of laccase activity [28-31].

\section{Dye decolorization experiments}

The previously described method of Ashrafi et al. [5] was used in order to assess the decolorization potential of the purified laccase. Firstly, dye solution was prepared by dissolving of each synthetic dye in citrate-phosphate buffer (100 mM, pH 5.0). Thereafter, the purified enzyme (final activity of $0.5 \mathrm{U} / \mathrm{mL}$ ) was inserted into each dye solution and the reaction mixture was incubated at $35^{\circ} \mathrm{C}$ and $50 \mathrm{rpm}$ for $3 \mathrm{~h}$. Subsequently, interval samples were taken each $30 \mathrm{~min}$ and the related absorbance (at the $\lambda_{\text {max }}$ of each dye, Table 1) was measured and decolorization percent was calculated using the below equation

$$
\text { Decolorization }(\%)=\left[\mathrm{A}_{\mathrm{i}}-\mathrm{A}_{\mathrm{t}} / \mathrm{A}_{\mathrm{i}}\right] \times 100
$$

where $A_{i}$ and $A_{t}$ are the initial absorbance and the absorbance after incubation time of the reaction mixture, respectively $[32,33]$. In order to confirm about significant change in decolorization percentage the reaction mixture was further incubated overnight. To examine the abiotic decolorization (negative control) each dye solution was inserted by heat-inactivated laccase and the related decolorization percent was estimated as said above. Three independent experiments were conducted for each dye and means of decolorization percent was calculated.

\section{The influence of $\mathrm{pH}$ alteration on enzymatic decolorization}

In order to investigate the influence of $\mathrm{pH}$ on laccasemediated decolorization each dye solution was firstly prepared in $0.1 \mathrm{M}$ citrate-phosphate buffer ( $\mathrm{pH} \mathrm{3-7)}$ ) or Tris- $\mathrm{HCl}$ buffer $(0.1 \mathrm{M}$ for $\mathrm{pH} 8)$ and the purified laccase $(0.5 \mathrm{U} / \mathrm{mL})$ was consequently added to the reaction mixture which was then monitored for decolorization as previously described.
The effect of temperature on laccase-mediated decolorization

After preparation of the reaction mixture including each studied dye and the purified laccase $(0.5 \mathrm{U} / \mathrm{mL})$ it was incubated at different temperatures $\left(5-75{ }^{\circ} \mathrm{C}\right)$ and decolorization percent was then determined using the previously described procedure.

\section{Laccase activity influence on dye decolorization}

The effect of enzyme concentration on decolorization process was evaluated by insertion of laccase (final activity range of $0.5-5 \mathrm{U} / \mathrm{mL}$ ) into the freshly prepared dye solution (in $0.1 \mathrm{M}$ citrate-phosphate buffer $\mathrm{pH}$ 5) and incubation at $35{ }^{\circ} \mathrm{C}$ and $50 \mathrm{rpm}$ for $1 \mathrm{~h}$ followed by recording of the related absorbance and calculation of the decolorization percent.

The effect of laccase mediator (HBT) on decolorization After dissolving of each dye into citrate-phosphate buffer (0.1 M pH 5) HBT was also inserted (final concentrations of 1,5 , and $10 \mathrm{mM}$ ) and decolorization was initiated by addition of laccase $(0.5 \mathrm{U} / \mathrm{mL})$ into the reaction mixture. The amount of decolorization was then demonstrated as mentioned above.

\section{The kinetics and energetics of dye elimination Decolorization kinetics}

In order to acquire the kinetic parameters of decolorization the related velocity $(\mathrm{V})$ was firstly obtained by performing dye decolorization at different concentrations $(C)$ of each dye. The Michaelis-Menten curve was then drawn by plotting the obtained velocity against concentration. Consequently, Lineweaver-Burk transformation was applied in order to obtain the kinetic constant $\left(K_{\mathrm{m}}\right.$ and $\left.V_{\text {max }}\right)$ of decolorization for each dye $[5,10]$.

\section{Decolorization thermodynamics}

The related velocity of decolorization was initially determined at various temperature of $10-50{ }^{\circ} \mathrm{C}$ and applied for drawing of a curve by plotting the calculated velocity against initial dye concentration. The apparent firstorder rate constant $(K)$ was then calculated based on the slope of the straight plot achieved for each dye and employed to drain the linearized Arrhenius curve by 
plotting the $\ln (\mathrm{K})$ versus $1 / \mathrm{T}\left(\times 10^{3} \mathrm{~K}^{-1}\right)$ where $\mathrm{T}$ is the absolute temperature (K). The slope of Arrhenius plot indicates $-E_{a} / R$ in which $E a$ is the activation energy and $\mathrm{R}$ is the gas constant $(8.3145 \mathrm{~J} / \mathrm{mol} / \mathrm{K})$. Thereafter, Van't Hoff curve was drained by plotting the $\ln \left(\mathrm{K}_{\text {eq }}\right)$ against $1 / \mathrm{T}\left(\times 10^{3} \mathrm{~K}^{-1}\right)$ and applied for determination of the entropy $(\Delta S)$ and enthalpy $(\Delta \mathrm{H})$ of decolorization reaction. $\mathrm{K}_{\mathrm{eq}}$ is the apparent equilibrium constant which was determined from difference of initial and remained dye concentration at equilibrium state, when the decolorization percentage become constant and no decolorization was occurred with passing the time [34]. Subsequently, the Gibbs free energy $(\Delta G)$ was also calculated using the equation of $\Delta \mathrm{G}=\Delta \mathrm{H}-\mathrm{T} \Delta \mathrm{S}$.

\section{Dye toxicity}

A modified microtoxicity assay procedure using six standard bacterial strain (three Gram-negative and three Gram-positive species, Table 2) was employed to determine the toxicity of each studied dye before and after treatment by the purified laccase. In brief, a proper dilution of each bacterial suspension $\left(\mathrm{OD}_{600}\right.$ 0.2 ) in Muller-Hinton broth medium was firstly prepared and successively inserted by each dye or its related laccase-treated solution and incubated at $37{ }^{\circ} \mathrm{C}$ for $10 \mathrm{~h}$. Afterwards, interval samples were taken every $2 \mathrm{~h}$ and analyzed for changes in the $\mathrm{OD}_{600}$ compared to that of the negative control (cultivated bacterial strain in the absence of any dye). The equation of $\left[\left(1-\mathrm{OD}_{6005} / \mathrm{OD}_{600 \mathrm{C}}\right) \times 100\right]$ was then utilized for determination of growth inhibition percent (GI\%), where $\mathrm{OD}_{6005}$ and $\mathrm{OD}_{600 \mathrm{C}}$ are $\mathrm{OD}_{600}$ of sample and $\mathrm{OD}_{600}$ of control, respectively.

\section{Statistical analysis}

Three replicates of each above mentioned experiment was performed and mean \pm standard deviation of each value was reported. In order to calculate the statistical significance (probability values less than 0.05 ) between mean values the independent sample $t$-test and one-way analysis of variance (ANOVA) with Dunnett's T3 post hoc test were employed using the SPSS software (version 15.0, SPSS Inc).

\section{Results and discussion \\ Decolorization studies}

As presented in the time course of decolorization of six synthetic azo dyes (Fig. 2), laccase was able to efficiently decolorize all studied dyes within $3 \mathrm{~h}$ incubation. Acid Orange 67, Disperse Yellow 79, Basic Yellow 28, Basic Red 18, Direct Yellow 107, and Direct Black 166 were respectively decolorized up to $65.3,53.3,46.7,40.7,34$, and $26.2 \%$ after $1 \mathrm{~h}$ treatment with laccase. Elongation of the reaction time to 24 h didn't significantly enhance decolorization percent (data not shown). Furthermore, for abiotic control (the reaction mixture without enzyme) no decolorization was observed indicating the catalytic role of laccase in the decolorization procedure.

Application of laccases and laccase mediated system (LMS) to decolorize mutagenic and carcinogenic synthetic colorants has been received great interest during two last decades [17, 35]. Literature review revealed that laccase assisted decolorization pattern even in the case of one special dye could vary depends on the origin of laccases $[1,10]$. There are many reports about decolorization ability of laccase and laccase mediated systems toward a broad range of synthetic dyes including diazo dyes, anthraquinone dyes, triphenylmethane dyes, and textile colorants $[2,5,24]$. The obtained results of the present study revealed the potential application of laccase for decolorization of six synthetic azo dyes (Fig. 2). Literature review introduced azo dyes as recalcitrant dyes using both the enzymatic and physicochemical procedures $[1,13]$. In general, resistance of azo colorants to laccase-catalyzed oxidation enhanced by increasing the number of azo group [36, 37]. For example, Ashrafi et al. [5] achieved the lowest and highest decolorization percent for Direct Blue 71 (a triazo dye,

Table 2 Growth inhibition percent (Gl\%) of untreated and laccase-treated dyes against six bacterial strains. Values are averages of three replicates \pm standard deviation

\begin{tabular}{|c|c|c|c|c|c|c|c|c|c|c|c|c|}
\hline \multicolumn{13}{|l|}{ Bacterial strains } \\
\hline \multirow[t]{2}{*}{ Dye names } & \multicolumn{2}{|l|}{ E. coli } & \multicolumn{2}{|c|}{ P. aeroginosa } & \multicolumn{2}{|l|}{ S. typhi } & \multicolumn{2}{|l|}{ B. subtilis } & \multicolumn{2}{|l|}{ S. aureus } & \multicolumn{2}{|l|}{ M. luteus } \\
\hline & $\overline{U^{a}}$ & $\mathrm{~T}^{\mathrm{b}}$ & U & $\mathrm{T}$ & U & $\mathrm{T}$ & U & $\mathrm{T}$ & U & $\mathrm{T}$ & $U$ & $\mathrm{~T}$ \\
\hline Acid Orange 67 & $28 \pm 1.1$ & $19 \pm 0.5^{*}$ & $21 \pm 0.4$ & $13 \pm 0.6^{*}$ & $24 \pm 0.8$ & $16 \pm 0.4^{*}$ & $37 \pm 1.1$ & $28 \pm 1.0^{*}$ & $33 \pm 1.8$ & $20 \pm 0.8^{*}$ & $42 \pm 2.3$ & $31 \pm 0.6$ \\
\hline Basic Red 18 & $25 \pm 1.1$ & $14 \pm 0.4^{*}$ & $18 \pm 1.2$ & $8 \pm 0.3^{*}$ & $23 \pm 1.2$ & $11 \pm 0.7^{*}$ & $34 \pm 1.5$ & $21 \pm 0.5^{*}$ & $30 \pm 1.1$ & $19 \pm 0.6^{*}$ & $37 \pm 0.8$ & $23 \pm 0.7^{*}$ \\
\hline Basic Yellow 28 & $32 \pm 1.8$ & $20 \pm 0.4^{*}$ & $26 \pm 1.4$ & $16 \pm 0.3^{*}$ & $29 \pm 1.3$ & $17 \pm 0.6^{*}$ & $41 \pm 1.9$ & $30 \pm 0.7^{*}$ & $36 \pm 0.7$ & $28 \pm 0.6^{*}$ & $49 \pm 1.2$ & $35 \pm 1.1^{*}$ \\
\hline Disperse Yellow 79 & $21 \pm 0.9$ & $9 \pm 0.4^{*}$ & $14 \pm 0.7$ & $5 \pm 0.3^{*}$ & $18 \pm 0.3$ & $7 \pm 0.4^{*}$ & $27 \pm 0.4$ & $12 \pm 0.2^{*}$ & $23 \pm 0.9$ & $9 \pm 0.3^{*}$ & $30 \pm 1.1$ & $16 \pm 0.5^{*}$ \\
\hline Direct Yellow 107 & $46 \pm 1.4$ & $34 \pm 0.4^{*}$ & $38 \pm 1.0$ & $29 \pm 0.3^{*}$ & $41 \pm 0.8$ & $31 \pm 0.8^{*}$ & $57 \pm 0.6$ & $44 \pm 0.6^{*}$ & $49 \pm 0.9$ & $41 \pm 0.9^{*}$ & $62 \pm 0.7$ & $48 \pm 0.7^{*}$ \\
\hline Direct Black 166 & $51 \pm 1.8$ & $37 \pm 0.7^{*}$ & $43 \pm 1.2$ & $30 \pm 0.6^{*}$ & $47 \pm 1.9$ & $31 \pm 0.8^{*}$ & $61 \pm 2.2$ & $50 \pm 0.9^{*}$ & $56 \pm 2.1$ & $45 \pm 0.8^{*}$ & $68 \pm 2.9$ & $54 \pm 1.0^{*}$ \\
\hline
\end{tabular}

${ }^{\mathrm{a}} \mathrm{Gl} \%$ in presence of untreated dye solution; ${ }^{\mathrm{b}} \mathrm{Gl} \%$ in presence of laccase-treated dye solution; ${ }^{*}$ Significancy was determined using independent sample $t$-test $(p$-value $<0.05$ ) 


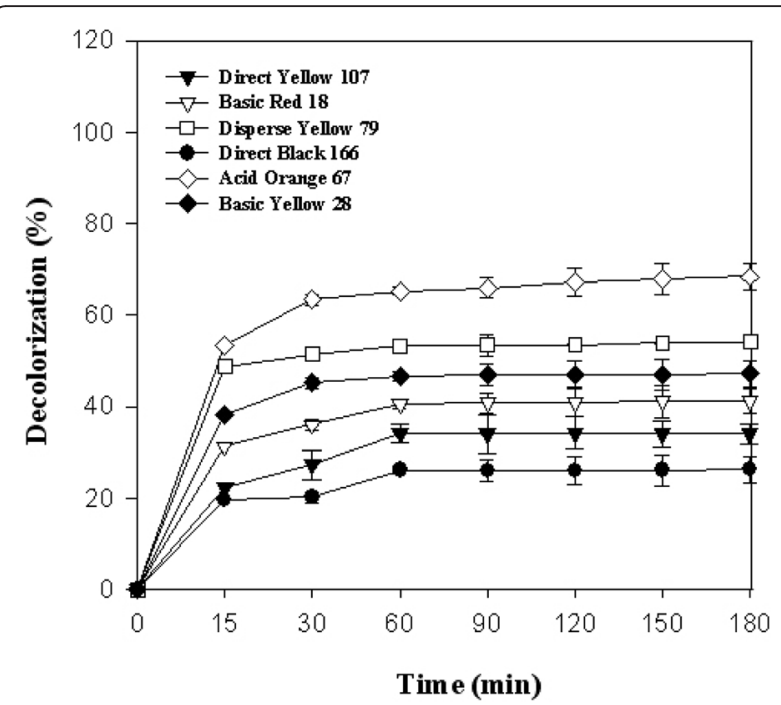

Fig. 2 Laccase mediated $(0.5 \mathrm{U} / \mathrm{mL})$ decolorization profiles of applied dyes during $180 \mathrm{~min}$ of incubation at $35^{\circ} \mathrm{C}$

$30 \%$ ) and Acid Red 18 (a monoazo dye, 97 \%), respectively, after $15 \mathrm{~min}$ treatment using the secreted laccase of $P$. varibile. In the study of Zeng et al. [38] it was found that the laccase originated by $T$. trogii SYBC-LZ didn't decolorize Acid Red 1 (a monoazo dye) and Reactive Black 5 (a diazo dye) while the highest decolorization percent $(80.4 \%)$ achieved for the anthraquinonic dye of Remazol Brilliant Blue $\mathrm{R}$ (RBBR). Grassi et al. [8] demonstrated that only $7 \%$ of Fast Blue $\mathrm{RR}$ (an azo dye) was removed after $1 \mathrm{~h}$ incubation in the presence of the purified laccase of $T$. trogii while more than $80 \%$ of anthraquinonic dye of RBBR and Indigo Carmine was eliminated at the same time.

\section{The influence of $\mathrm{pH}$ and temperature on laccase-catalyzed decolorization}

The results of $\mathrm{pH}$ alteration on decolorization of investigated dyes were illustrated in Fig. 3a. Maximum decolorization of all dyes occurred at the optimum $\mathrm{pH}$ of the applied laccase (5) which previously reported by Forootanfar et al. [25]. Alteration from the optimum $\mathrm{pH}$ of laccase negatively affected decolorization percent of all synthetic dyes. In the study of Ashrafi et al. [5] and Mirzadeh et al. [10] laccase mediated decolorization of all applied dyes was maximally achieved at acidic $\mathrm{pH}$ of 5 . It was demonstrated that most of laccases of fungal origins maximally work at acidic $\mathrm{pH}$ and the enzyme activity at higher $\mathrm{pH}$ is decreased due to binding of hydroxide anion to the T2/T3 coppers of laccase and as a result interrupting with the internal electron transfer from $\mathrm{T} 1$ to $\mathrm{T} 2 / \mathrm{T} 3$ centers [39].

Decolorization percent of all studied dyes was gradually increased by enhancing the reaction temperature and maximum decolorization of Disperse Yellow 79 (60\%), Acid Orange 67 (71.3\%), and Basic Yellow 28 (58.4\%) was observed at the temperature of $45{ }^{\circ} \mathrm{C}$ (Fig. 3b). Basic Red 18 (48 \%), Direct Yellow 107 (50.2 \%), and Direct Black 166 (46 \%) were maximally decolorized at $55{ }^{\circ} \mathrm{C}$ (Fig. 3b). The amount of decolorization of all studied dyes was dropped below $20 \%$ ( $p$-value $<0.05)$ by elevating of temperature to $70{ }^{\circ} \mathrm{C}$ which was in agreement with the acquired results of Ashrafi et al. [5] who observed that maximum dye decolorization occurred between the temperatures of $40-60{ }^{\circ} \mathrm{C}$. In general, most of the fungal derived laccases optimally work at the temperature range of 50 $70{ }^{\circ} \mathrm{C}[39]$.

\section{The effect of laccase activity on decolorization}

As represented in Fig. 4a, the decolorization percent of all studied dyes (except for Acid Orange 67) was significantly enhanced ( $p$-value $<0.05)$ after increasing of laccase activity from $0.5 \mathrm{U} / \mathrm{mL}$ to $1 \mathrm{U} / \mathrm{mL}$. MaalejKammoun et al. [6] determined decolorization percent of $80 \%$ for laccase-catalyzed $(1 \mathrm{U} / \mathrm{mL})$ elimination of Malachite green within $2 \mathrm{~h}$ of initiation of the reaction. In the study of Ashrafi et al. [5] it was showed that increasing of laccase activity from 0.025 to $0.1 \mathrm{U} /$ $\mathrm{mL}$ significantly increased decolorization percent of all thirteen studied synthetic dyes.

\section{The influence of HBT on laccase mediated decolorization}

As represented in Fig. 4b, decolorization percent of all synthetic dyes was positively affected by increasing of HBT concentration up to $5 \mathrm{mM}$ and decreased by enhancing the HBT concentration more than $5 \mathrm{mM}$.

Treatment of hazardous organic pollutants and synthetic dyes using laccase-mediated systems, especially in the case of laccases with low redox potential and recalcitrant pollutants, has been well documented [22] For example, Ostadhadi-Dehkordi et al. [40] investigated on the mediating activity of the phenol derivatives of vanillic acid (VA) and 2,6-dimethoxyphenol (DMP) and the non-phenolic mediators (ABTS and HBT), among which HBT was the most efficient one increased the removal percent of four investigated benzodiazepines (one of the most prescribed pharmaceuticals). Grassi et al. [8] evaluated the effect of synthetic (HBT) and several natural laccase mediators including $\rho$-hydroxybenzoic acid (HBA), tyrosine, vanillin, vanillic acid, anisaldehyde, and ferulic acid on decolorization of Azure B, Xylidine, and Gentian Violet in the presence of $T$. trogii's laccase. They introduced HBT as the best mediator for maximum decolorization [8]. LaccaseHBT system is generally more effective compared to unaided laccase due to stronger oxidative activity of free-radical HBT species. Furthermore, high redox 


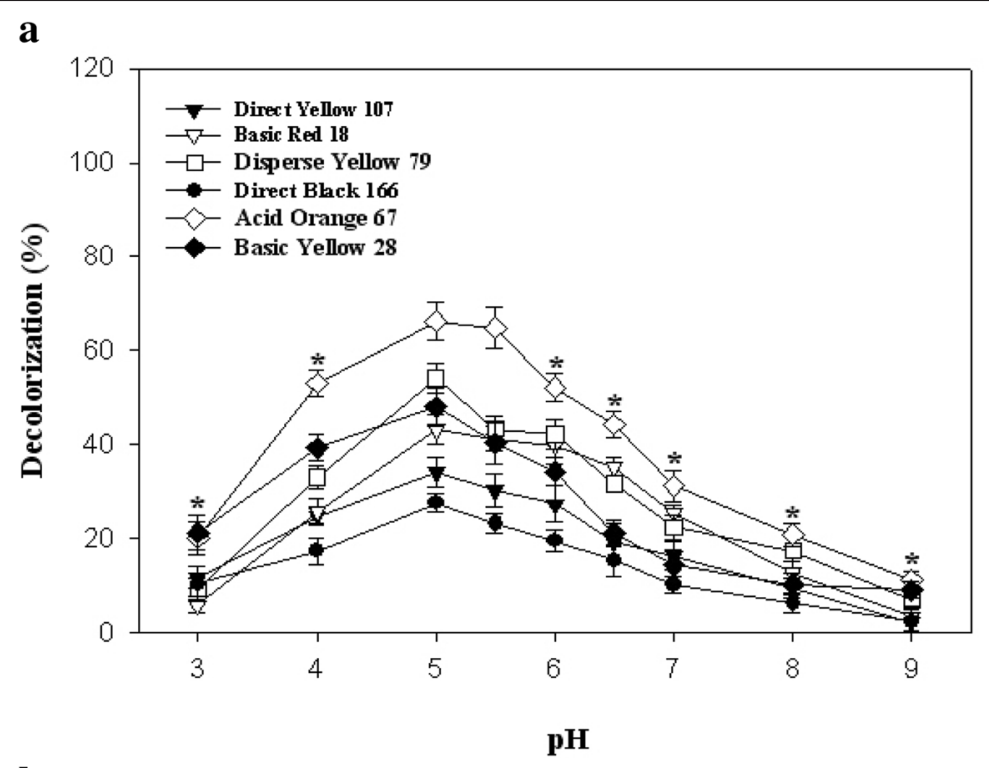

b

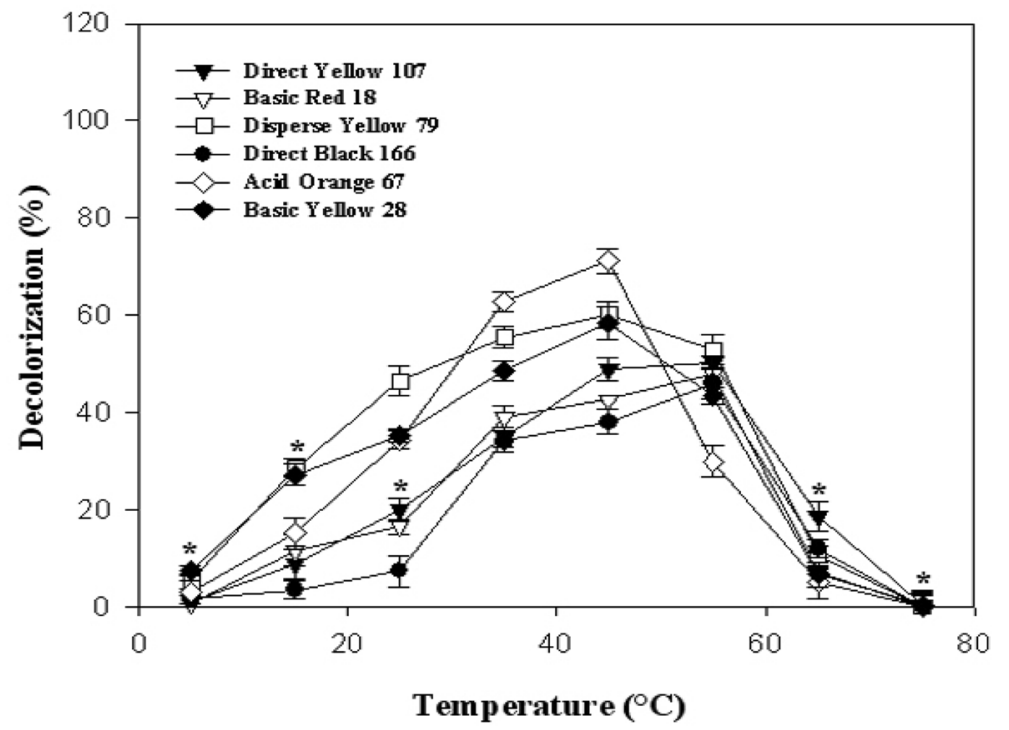

Fig. 3 Effect of various (a) pH, and (b) temperatures on decolorization of azo dyes using the purified laccase $(0.5 \mathrm{U} / \mathrm{mL})$ after $60 \mathrm{~min}$ of incubation. Obtained means were analyzed by ANOVA with Dunnett's T3 post hoc test ${ }^{*}, p$-value $\left.<0.05\right)$

potential of HBT $(1084 \mathrm{mV})$ together with the stabilizing activity of HBT on laccases makes it suitable for elimination of recalcitrant colorants using oxidative activity of laccases [22, 40]. However, depend on the source of laccases applied in the elimination studies, there is a critical concentration above which the assisting activity of this non-phenolic laccase mediator is negatively affected by the destructive effect of produced HBT radical on enzyme structure [22]. So, literature review revealed many reports on determination of optimum concentration of HBT to get maximum decolorization using laccase-HBT system $[5,40]$.

\section{Kinetics and energetic studies}

Based on the kinetic parameters of the laccase toward studied dyes (Tabale 1) the lowest and the highest $K_{m}$ value belonged to the monoazo dye of Acid Orange 67 $(0.49 \mathrm{mM})$ and triazo dye of Direct Black 166 (4.25 mM), respectively. Unsuitability of Direct Black 166 as a laccase substrate is evident from the high value of the calculated $K_{m}$ of this colorant $(4.25 \mathrm{mM})$ and its related maximum velocity $(33 \mathrm{mmol} / \mathrm{min} / \mathrm{mg}$ ). The resistance of azo dyes to laccase-catalyzed oxidation compared to other classes of colorants has been well documented. Grassi et al. [8] reported the lowest 


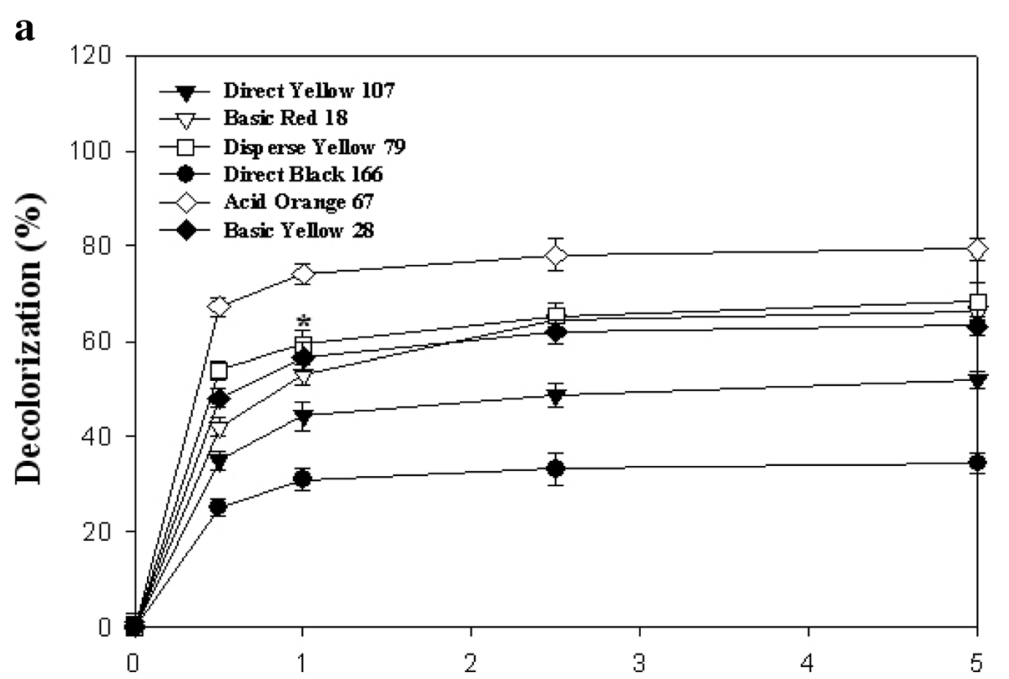

Laccase activity $(\mathrm{U} / \mathrm{ml})$

b

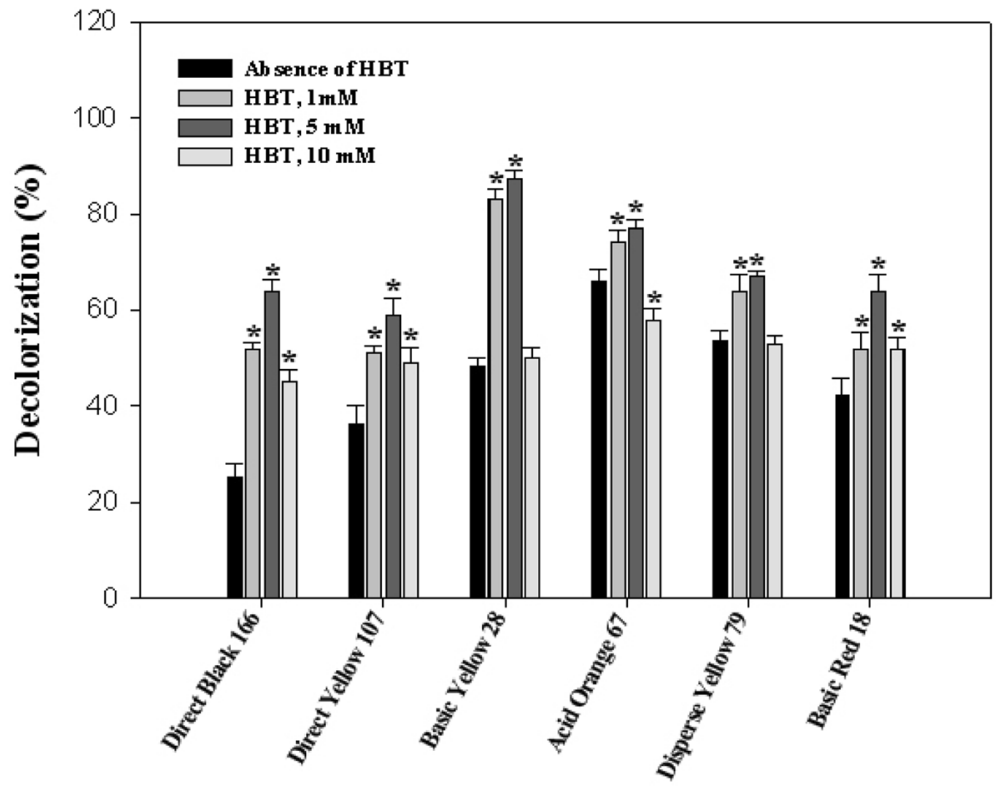

Fig. 4 Influence of (a) laccase activity and (b) HBT concentration on decolorization of investigated dyes after 60 min of incubation at $35^{\circ} \mathrm{C}$. Significant values (*, $p$-value $<0.05$ ) were achieved after ANOVA analysis with Dunnett's T3 post hoc test

decolorization percent for the azo dye of Fast Blue RR using the purified laccase of $T$. trogii B6J among tested synthetic dyes. Generally, presence of electron withdrawing groups such as $-\mathrm{SO}_{3} \mathrm{H},-\mathrm{SO}_{2} \mathrm{NH}_{2}$ together with the high molecular weight decreases the ability of laccases for elimination of azo dyes [1]. Application of laccases harboring higher redox potential such as bacterial laccases and addition of synthetic or natural redox mediators are two main solutions to overcome such problem [1]. As an example, the recombinant bacterial CotA-laccase from $B$. subtilis was able to decolorize Direct Blue 1 (a diazo dye), Reactive Black
5 (a diazo dye), and Sudan Orange G (a monoazo dye) by 88,85 and $98 \%$, respectively at alkaline $\mathrm{pH}$ and in the absence of redox mediators [9].

The obtained results of energetic assessment for laccase-mediated decolorization (Table 1) indicated the significant influence of temperature on decolorization of all investigated synthetic dyes as decolorization rate increased from $10{ }^{\circ} \mathrm{C}$ to $50{ }^{\circ} \mathrm{C}$. The activation energies (calculated from the slope of Arrhenius plot) together with the estimated values for $\Delta \mathrm{H}$ and $\Delta \mathrm{S}$ were also represented in Table 1 . Considering the negative amount of slope obtained for van't Hoff plot or the positive 
signs of $\Delta \mathrm{H}$ (Table 1) it was demonstrated that the decolorization reactions are endothermic.

\section{Microtoxicity study}

The results of microtoxicity study were summarized in Table 2. The highest GI\% belonged to the Direct Black 166 (a triazo dye) suppressing M. luteus, S. aureus, B. subtilis, E. coli, P. aeruginosa, and $S$. typhi by $68,56,61$, 51,43 , and $47 \%$, respectively, when exposed to each bacterial strain for $10 \mathrm{~h}$. On the other hand, the monoazoic dye of Disperse Yellow 79 represented GI\% of 30, 23, 27, 21, 14, and $18 \%$ for M. luteus, S. aureus, B. subtilis, E. coli, P. aeruginosa, and S. typhi, respectively (Table 2) which was the lowest observed value. The GI\% of all synthetic azo dyes was significantly reduced following laccase treatment as presented in Table 2.

In order to evaluate the probable toxicity of colorants and their metabolite(s) after physicochemical or biological treatment many biological assays such as inhibition the growth of bacterial, yeast, and mammalian cell lines as well as phytotoxicity evaluations on plant seeds were developed [5, 9, 41, 42]. Like the acquired results reported by Ashrafi et al. [5] the attained results of the present investigation showed that the toxicity of all applied dyes was significantly decreased after addition of laccase to dye solution. Younes et al. [13] found that the GI\% of Bacillus megaterium was enhanced from 2 to $99 \%$ after incubation of malachite green in the presence of purified laccase originated from S. thermophilum. Maalej-Kammoun et al. [6] reported that decolorization of malachite green resulted in the removal of its toxicity against Phanerochaete chrysosporium. However, Mendes et al. [14] found lower toxicity for intact azo dyes of Direct Black 38, Direct Red 80, Reactive Black 5, Reactive Yellow 145, Acid Black 194, and Acid Red 266 compared to that of laccase-treated sample in the presence of the yeast $S$. cerevisiae.

\section{Conclusion}

The potential activity of the purified laccase of $P$. variabile for decolorization of 6 azo dyes in the presence and absence of HBT as the laccase mediator was evaluated. All the synthetic dyes were decolorized using non-assisted laccase. In addition, decolorization percent of all applied colorants improved in the presence of HBT (up to $5 \mathrm{mM}$ ) as laccase mediator. Evaluation the toxicity of laccasetreated dye samples assisted by growth inhibition percentage (GI\%) of standard bacterial strains revealed significant decrease in the toxicity of all studied dyes after treatment by laccase.

\section{Competing interests}

The authors declare that they have no competing interests.

\section{Authors' contributions}

Decolorization studies were performed by HT and HZ-L. Laccase of $P$. variabile was purified by HF. SR involved in the studies of decolorization kinetic. MM performed decolorization studies and writing of the manuscript. Microtoxicity investigations were carried out by AA. MAF involved in purchasing of required materials and instruments, designing of decolorization experiments, analyzing of data and reviewing of the manuscript. All authors read and approved the final manuscript.

\section{Acknowledgement}

This work was financially supported by a grant from Tehran University of Medical Sciences, Tehran, Iran to M.A.F.

\section{Author details}

'Department of Pharmaceutical Biotechnology, Faculty of Pharmacy, Kerman University of Medical Sciences, Kerman, Iran. ${ }^{2}$ Department of Pharmaceutical Biotechnology, Faculty of Pharmacy and Biotechnology Research Center, Tehran University of Medical Sciences, P.O. Box 14155-6451, Tehran 1417614411 , Iran. ${ }^{3}$ Department of Pharmacology and Toxicology, Faculty of Pharmacy, Tehran University of Medical Sciences, P.O. Box 14155-6451, Tehran 1417614411, Iran. ${ }^{4}$ Department of Medicinal Chemistry, Faculty of Pharmacy, Kerman University of Medical Sciences, Kerman, Iran.

Received: 11 September 2015 Accepted: 9 May 2016

Published online: 13 May 2016

\section{References}

1. Saratale RG, Saratale GD, Chang JS, Govindwar SP. Bacterial decolorization and degradation of azo dyes: a review. J Taiwan Inst Chem Eng. 2011;42:138-57.

2. Forootanfar H, Moezzi A, Aghaie-Khouzani M, Mahmoudjanlou Y, Ameri A, Niknejad F, Faramarzi MA. Synthetic dye decolorization by three sources of fungal laccase. J Environ Health Sci Eng. 2012;9:27.

3. Rezaie S, Tahmasbi H, Mogharabi M, Firuzyar S, Ameri A, Khoshayand MR, Faramarzi MA. Efficient decolorization and detoxification of reactive orange 7 using laccase isolated from paraconiothyrium variabile, kinetics and energetics. J Taiwan Inst Chem Eng. 2015;56:1-9.

4. Rezaie S, Tahmasbi H, Mogharabi M, Ameri A, Forootanfar H, Khoshayand MR, Faramarzi MA. Laccase-catalyzed decolorization and detoxification of Acid Blue 92: statistical optimization, microtoxicity, kinetics, and energetics. J Environ Health Sci Eng. 2015;13:31.

5. Ashrafi SD, Rezaei S, Forootanfar H, Mahvi AH, Faramarzi MA. The enzymatic decolorization and detoxification of synthetic dyes by the laccase from a soil-isolated ascomycete, Paraconiothyrium variabile. Int Biodeter Biodegr. 2013;85:173-81.

6. Maalej-Kammoun M, Zouari-Mechichi H, Belbahri L, Woodward S, Mechichi T. Malachite green decolourization and detoxification by the laccase from a newly isolated strain of Trametes sp. Int Biodeter Biodegr. 2009:63:600-6.

7. Shirmardi M, Mesdaghinia A, Mahvi AH, Nasseri S, Nabizadeh R. Kinetics and equilibrium studies on adsorption of acid red 18 (Azo-Dye) using multiwall carbon nanotubes (MWCNTs) from aqueous solution. E-J Chem. 2012;9:2371-83.

8. Grassi E, Scodeller P, Filiel N, Carballo R, Levin L. Potential of Trametes trogii culture fluids and its purified laccase for the decolorization of different types of recalcitrant dyes without the addition of redox mediators. Int Biodeter Biodegr. 2011;65:635-43.

9. Pereira L, Coelho AV, Viegas CA, Santos MM C d, Robalo MP, Martins LO. Enzymatic biotransformation of the azo dye Sudan orange $\mathrm{G}$ with bacterial CotA-laccase. J Biotechnol. 2009;139:68-77.

10. Mirzadeh SS, Khezri SM, Rezaei S, Forootanfar H, Mahvi AH, Faramarzi MA Decolorization of two synthetic dyes using the purified laccase of Paraconiothyrium variabile immobilized on porous silica beads. J Environ Health Sci Eng. 2014;12:6.

11. Maleki A, Mahvi AH, Ebrahimi R, Zandsalimi Y. Study of photochemical and sonochemical processes efficiency for degradation of dyes in aqueous solution. Korean J Chem Eng. 2010;27:1805-10.

12. Mahvi $\mathrm{AH}$, Ghanbarian M, Nasseri S, Khairi A. Mineralization and discoloration of textile wastewater by $\mathrm{TiO}_{2}$ nanoparticles. Desalination. 2009;239:309-16.

13. Younes SB, Bouallagui Z, Sayadi S. Catalytic behavior and detoxifying ability of an atypical homotrimeric laccase from the thermophilic strain Scytalidium thermophilum on selected azo and triarylmethane dyes. J Mol Catal B Enzym. 2012;79:41-8. 
14. Mendes S, Farinha A, Ramos CG, Leitao JH, Viegas CA, Martins LO. Synergistic action of azoreductase and laccase leads to maximal decolourization and detoxification of model dye-containing wastewaters. Bioresour Technol. 2011:102:9852-9.

15. Asadgol Z, Forootanfar $H$, Rezaie S, Mahvi AH, Faramarzi MA. Removal of phenol and bisphenol-A catalyzed by laccase in aqueous solution. J Environ Health Sci Eng. 2014;12:93.

16. Faramarzi MA, Forootanfar $\mathrm{H}$. Biosynthesis and characterization of gold nanoparticles produced by laccase from Paraconiothyrium variabile. Colloid Surf B. 2011;87:23-7.

17. Mogharabi M, Faramarzi MA. Laccase and laccase-mediated systems in the synthesis of organic compounds. Adv Synth Catal. 2014;356:897-927.

18. Forootanfar $\mathrm{H}$, Faramarzi MA. Insights into laccase producing organisms, fermentation states, purification strategies, and biotechnological applications. Biotechnol Prog. 2015;31:1443-63.

19. Forootanfar H, Movahednia MM, Yaghmaei S, Tabatabaei-Sameni M, Rastegar H, Sadighi A, Faramarzi MA. Removal of chlorophenolic derivatives by soil isolated ascomycete of Paraconiothyrium variabile and studying the role of its extracellular laccase. J Hazard Mater. 2012;209-210:199-203.

20. Dehghanifard E, Jafari AJ, Kalantary RR, Mahvi AH, Faramarzi MA, Esrafili A. Biodegradation of 2,4-dinitrophenol with laccase immobilized on nanoporous silica beads. J Environ Health Sci Eng. 2013;10:25.

21. Rahmani K, Faramarzi MA, Mahvi AH, Gholami M, Esrafili A, Forootanfar H, Farzadkia M. Elimination and detoxification of sulfathiazole and sulfamethoxazole assisted by laccase immobilized on porous silica beads. Int Biodeter Biodegr. 2015;97:107-14.

22. Canas Al, Camarero S. Laccases and their natural mediators: biotechnological tools for sustainable eco-friendly processes. Biotechnol Adv. 2010;28:694-705.

23. Ashrafi SD, Nasseri S, Alimohammadi M, Mahvi AH, Faramarzi MA. Optimization of the enzymatic elimination of flumequine by laccasemediated system using response surface methodology. Desalin Water Treat doi:10.1080/19443994.2015.1063462.

24. Aghaie-Khouzani M, Forootanfar H, Moshfegh M, Khoshayand MR, Faramarzi MA. Decolorization of some synthetic dyes using optimized culture broth of laccase producing ascomycete Paraconiothyrium variabile. Biochem Eng J. 2012;60:9-15.

25. Forootanfar H, Faramarzi MA, Shahverdi AR, Tabatabaei Yazdi M. Purification and biochemical characterization of extracellular laccase from the ascomycete Paraconiothyrium variabile. Bioresour Technol. 2011;102:1808-14.

26. Mendoza $L$, Jonstrup M, Hatti-Kaul R, Mattiasson B. Azo dye decolorization by a laccase/mediator system in a membrane reactor: enzyme and mediator reusability. Enzyme Microb Technol. 2011;49:478-84.

27. Yan J, Chen D, Yang E, Niu J, Chen Y, Chagan I. Purification and characterization of a thermotolerant laccase isoform in Trametes trogii strain and its potential in dye decolorization. Int Biodeter Biodegr. 2014;93:186-94.

28. Sadighi A, Faramarzi MA. Congo red decolorization by immobilized laccase through chitosan nanoparticles on the glass beads. J Taiwan Inst Chem Eng. 2013;44:156-62.

29. Zeinvand-Lorestani H, Sabzevari O, Setayesh N, Amini M, Nili-Ahmadabadi A, Faramarzi MA. Comparative study of in vitro prooxidative properties and genotoxicity induced by aflatoxin B1 and its laccase-mediated detoxification products. Chemosphere. 2015;135:1-6.

30. Alberts JF, Gelderblom WCA, Botha A, Vanzyl WH. Degradation of flatoxin B1 by fungal laccase enzymes. Int J Food Microbiol. 2009;135:47-52.

31. Tahmasbi H, Khoshayand MR, Bozorgi-Koushalshahi M, Heidary M, GhaziKhansari M, Faramarzi MA. Biocatalytic conversion and detoxification of imipramine by the laccase-mediated system. Int Biodeter Biodegr. 2016;108:1-8.

32. Couto SR. Decolouration of industrial azo dyes by crude laccase from Trametes hirsuta. J Hazard Mater. 2007;148:768-70.

33. Khlifi R, Belbahri L, Woodward S, Ellouz M, Dhouib A, Sayadi S, Mechichi T. Decolourization and detoxification of textile industry wastewater by the laccase-mediator system. J Hazard Mater. 2010;175:802-8.

34. Annuar MSM, Adnan S, Vikineswary S, Chisti Y. Kinetics and energetics of azo dye decolorization by Pycnoporus sanguineus. Water Air \& Soil Poll. 2009; 202:179-88.

35. Roriz MS, Osma JF, Teixeira JA, Couto SR. Application of response surface methodological approach to optimize reactive black 5 decolouration by crude laccase from trametes pubescens. J Hazard Mater. 2009;169:691-6.

36. Gholami-Borujeni F, Mahvi AH, Nasseri S, Faramarzi MA, Nabizadeh R, Alimohammadi M. Enzymatic treatment and detoxification of acid orange 7 from textile wastewater. Appl Biochem Biotechnol. 2011;165:1274-84.
37. Gholami-Borujeni F, Faramarzi MA, Nabizadeh-Barandozi R, Mahvi AH. Oxidative degradation and detoxification of textile azo dye by horseradish peroxidase enzyme. Fresen Environ Bull. 2013;22:739-44.

38. Zeng X, Cai Y, Liao X, Zeng X, Li W, Zhang D. Decolorization of synthetic dyes by crude laccase from a newly isolated Trametes trogii strain cultivated on solid agro-industrial residue. J Hazard Mater. 2011;187:517-25.

39. Baldrian P. Fungal laccases -occurrenceand properties. FEMS Microbiol Rev. 2006;30:215-42.

40. Ostadhadi-Dehkordi S, Tabatabaei-Sameni M, Forootanfar H, Kolahdouz S, Ghazi-Khansari M, Faramarzi MA. Degradation of some benzodiazepines by a laccase-mediated system in aqueous solution. Bioresour Technol. 2012; 125:344-7.

41. Zhuo R, Ma L, Fan F, Gong Y, Wan X, Jiang M, Zhang X, Yang Y. Decolorization of different dyes by a newly isolated white-rot fungi strain Ganoderma sp. En3 and cloning and functional analysis of its laccase gene. J Hazard Mater. 2011;192:855-73.

42. Gholami-Borujeni F, Mahvi AH, Nasseri S, Faramarzi MA, Nabizadeh R, Alimohammadi M. Application of immobilized horseradish peroxidase for removal and detoxification of azo dye from aqueous solution. Res J Chem Environ. 2011;15:217-22.

\section{Submit your next manuscript to BioMed Central and we will help you at every step:}

- We accept pre-submission inquiries

- Our selector tool helps you to find the most relevant journal

- We provide round the clock customer support

- Convenient online submission

- Thorough peer review

- Inclusion in PubMed and all major indexing services

- Maximum visibility for your research

Submit your manuscript at www.biomedcentral.com/submit
) Biomed Central 